\author{
Christine Watremez \\ Giuseppe Liistro \\ Marc deKock \\ Jean Roeseler \\ Thierry Clerbaux \\ Bruno Detry \\ Marc Reynaert \\ Pierre Gianello \\ Philippe Jolliet
}

\section{Effects of helium-oxygen on respiratory mechanics, gas exchange, and ventilation- perfusion relationships in a porcine model of stable methacholine-induced bronchospasm}

Received: 25 September 2002

Accepted: 27 March 2003

Published online: 16 May 2003

(C) Springer-Verlag 2003

An editorial regarding this article can be found in the same issue (http://dx.doi.org/10.1007/s00134-0031836-6)

\section{P. Jolliet ( $)$}

Division des soins intensifs de Médecine,

Hôpital Cantonal Universitaire,

1211 Geneva 14, Switzerland

e-mail: Philippe.Jolliet@medecine.unige.ch

Tel.: +41-22-3729093

Fax: +41-22-3729105

C. Watremez · M. deKock

Division of Anesthesiology,

Clinique Universitaire St.-Luc,

Brussels, Belgium

G. Liistro · T. Clerbaux · B. Detry

Division of Pneumology,

Clinique Universitaire St.-Luc,

Brussels, Belgium

J. Roeseler · M. Reynaert

Department of Emergency

and Intensive Care,

Clinique Universitaire St.-Luc,

Brussels, Belgium

P. Gianello

Laboratory of Experimental Surgery,

Clinique Universitaire St.-Luc,

Brussels, Belgium

\begin{abstract}
Objective: To explore the consequences of helium/oxygen $\left(\mathrm{He} / \mathrm{O}_{2}\right)$ inhalation on respiratory mechanics, gas exchange, and ventilation-perfusion (VA/Q) relationships in an animal model of severe induced bronchospasm during mechanical ventilation. Design: Prospective, interventional study. Setting: Experimental animal laboratory, university hospital. Interventions: Seven piglets were anesthetized, paralyzed, and mechanically ventilated, with all ventilator settings remaining constant throughout the protocol. Acute stable bronchospasm was obtained through continuous aerosolization of methacholine. Once steady-state was achieved, the animals successively breathed air/ $\mathrm{O}_{2}$ and $\mathrm{He} / \mathrm{O}_{2}\left(\mathrm{FIO}_{2} 0.3\right)$, or inversely, in random order. Measurements were taken at baseline, during bronchospasm, and after $30 \mathrm{~min}$ of $\mathrm{He} / \mathrm{O}_{2}$ inhalation. Results: Bronchospasm increased lung peak inspiratory pressure $\left(49 \pm 6.9\right.$ vs $18 \pm 1 \mathrm{~cm} \mathrm{H}_{2} \mathrm{O}$, $P<0.001)$, lung resistance $(22.7 \pm 1.5$ vs $6.8 \pm 1.5 \mathrm{~cm} \mathrm{H}_{2} \mathrm{O} .1^{-1}$.s, $\left.P<0.001\right)$, dynamic elastance $(76 \pm 11.2$ vs $\left.22.8 \pm 4.1 \mathrm{~cm} \mathrm{H}_{2} \mathrm{O} .1^{-1}, P<0.001\right)$, and work of breathing $(1.51 \pm 0.26 \mathrm{vs}$
\end{abstract}

$0.47 \pm 0.08, P<0.001)$. Arterial $\mathrm{pH}$ decreased $(7.47 \pm 0.06$ vs $7.32 \pm 0.06$, $P<0.001), \mathrm{PaCO}_{2}$ increased, and $\mathrm{PaO}_{2}$ decreased. Multiple inert gas elimination showed an absence of shunt, substantial increases in perfusion to low VA/Q regions, and dispersion of VA/Q distribution. $\mathrm{He} / \mathrm{O}_{2}$ reduced lung resistance and work of breathing, and worsened hypercapnia and respiratory acidosis. Conclusions: In this model, while $\mathrm{He} / \mathrm{O}_{2}$ improved respiratory mechanics and reduced work of breathing, hypercapnia and respiratory acidosis increased. Close attention should be paid to monitoring arterial blood gases when $\mathrm{He} / \mathrm{O}_{2}$ is used in mechanically ventilated acute severe asthma.

Keywords Asthma Methacholine . Respiratory mechanics . Ventilation/perfusion · MIGET . Helium

\section{Introduction}

Mechanical ventilation with endotracheal intubation is required in approximately $40 \%$ of patients admitted to the ICU for acute severe asthma (ASA) [1], and is re- sponsible for an increase in morbidity and mortality [1, $2,3,4]$. Barotrauma and severe hypotension resulting from high end-inspiratory pulmonary volume and intrinsic PEEP $[5,6]$ are the most frequently observed complications in these patients $[1,3,4]$. Due to its low density, 
helium/oxygen $\left(\mathrm{He} / \mathrm{O}_{2}\right)$ reduces the resistance to flow in the airways [7], and has been shown to improve peak inspiratory flow, dyspnea, and pulsus paradoxus in nonintubated patients with ASA [8,9], to increase arterial $\mathrm{pH}$ and decrease $\mathrm{PaCO}_{2}$ in intubated and mechanically ventilated patients $[10,11]$, and to improve respiratory mechanics in a mechanically ventilated animal model [12]. Thus, $\mathrm{He} / \mathrm{O}_{2}$ inhalation could be included in the management strategy of such patients. However, this approach raises some concerns. Indeed, the low density of helium can interfere with the pneumotachograph used by most ventilators to measure inspiratory flow and compute delivered tidal volume (VT), as these devices are normally calibrated for air/ $\mathrm{O}_{2}$ [13]. In turn, this can lead to improper tidal volume and $\mathrm{FIO}_{2}$ administration [13]. Furthermore, a worsening of hypoxemia with helium has been documented in obstructive airway disease $[14,15]$.

The purpose of this study was to explore the effects of $\mathrm{He} / \mathrm{O}_{2}$ inhalation on respiratory mechanics, gas exchange, and ventilation-perfusion relationships in a recently validated model of stable methacholine-induced bronchospasm mimicking ASA in intubated and mechanically ventilated piglets [16].

\section{Materials and methods}

Animals

The study was conducted in the Laboratory of Experimental Surgery, St.-Luc Hospital, in Brussels. The study protocol was approved by the ethics committee for animal experiments of the Catholic University of Louvain, Brussels. Eight young piglets (age 3-4 months) were used, and at the end of each experiment were killed using a solution of embutramide, mebenzonium iodide, and tetracaine (T61; Intervet, Mechelen, Belgium).

\section{Anesthesia and equipment}

The animals were anesthetized with intramuscular xylazine hydrochloride, $2 \mathrm{mg} . \mathrm{kg}^{-1}$, and tiletamin/zolazepam, $7.5 \mathrm{mg} . \mathrm{kg}^{-1}$, followed by intravenous propofol at a constant infusion rate of $2 \mathrm{mg} \cdot \mathrm{kg}^{-1} \cdot \mathrm{h}^{-1}$. Animals were placed in the supine position, intubated (6.5 mm internal diameter cuffed orotracheal tube), and mechanically ventilated with a Servo 900C ventilator (Siemens Elema, Solna, Sweden). Muscle paralysis throughout the experiment was obtained with i.v. pancuronium bromide $\left(0.1 \mathrm{mg} . \mathrm{kg}^{-1}\right.$ bolus, followed by a $0.2 \mathrm{mg} \cdot \mathrm{kg}^{-1} \cdot \mathrm{h}^{-1}$ constant infusion). Invasive blood pressure measurement and arterial blood gas sampling were obtained with a peripheral arterial catheter. A continuous cardiac output and mixed venous saturation pulmonary arterial catheter $\left(\mathrm{CCO}-\mathrm{SvO}_{2}\right.$ catheter; Baxter Edwards Laboratories, Irvine, Calif., USA) was inserted to allow measurements of cardiac output, blood temperature, mixed venous oxygen saturation $\left(\mathrm{SvO}_{2}\right)$, and the withdrawal of blood samples.

\section{Mechanical ventilation and basic monitoring}

Mechanical ventilation was performed in volume-controlled mode, adjusted to obtain normocapnia with a fraction of inspired oxygen $\left(\mathrm{FIO}_{2}\right)$ of 0.3 , no PEEP, and an inspiratory time of $33 \%$ with no inspiratory plateau. All ventilatory parameters and $\mathrm{FIO}_{2}$ were kept constant during the subsequent experimental phases. Heart rate, $\mathrm{SpO}_{2}$, end-tidal $\mathrm{CO}_{2}$, peak inspiratory pressure (PIP), and mean inspiratory pressure were monitored.

\section{Respiratory system mechanics}

An esophageal balloon (International Medical Products, Kleve, The Netherlands) filled with $1 \mathrm{cc}$ air was connected to a $\pm 140 \mathrm{~cm} \mathrm{H}_{2} \mathrm{O}$ differential pressure transducer (Validyne Engineering, North Ridge, Calif., USA). The balloon was positioned to obtain a representative pleural pressure tracing according to standard technique [17] and checked using the occlusion test [18]. Airflow ( $\mathrm{V})$ was measured by a Fleisch $\mathrm{N}^{\circ} 2$ pneumotachograph (Fleisch, Lausanne, Switzerland). Volume (V) was obtained by electrical integration of the flow signal. The pneumotachograph was calibrated by placing it in series with a dry gasometer (Parkinson and Cowan CD4, Manchester, UK), and passing the two gas mixtures, i.e., air/ $\mathrm{O}_{2} 70: 30$ and $\mathrm{He} / \mathrm{O}_{2} 70: 30$ through this setup. A T-tube was placed between the ventilator and the pneumotachograph, and connected to both the other port of the pressure transducer used for esophageal pressure, to measure transpulmonary pressure, and to a second $140 \mathrm{~cm} \mathrm{H}_{2} \mathrm{O}$ differential pressure transducer, for the measurement of airway pressure. Pressure, V, and V signals were recorded on paper with a TA 11 electrostatic recorder (Gould Instruments, Valley View, Ohio, USA), then scanned and digitalized (Un-Scan-It; Silk Scientific, Orem, Vt., USA). Lung resistance (Rl) and dynamic elastance (Ed) were calculated by multiple linear analysis [19] fitting of the equation of motion:

$\mathrm{Ptp}=\mathrm{Ed} \cdot \mathrm{V}+\mathrm{Rl} \cdot \mathrm{V}^{\prime}+\mathrm{k}$

where Ptp is the transpulmonary pressure and $\mathrm{k}$ is a constant. Tracheal tube resistance was not subtracted from Rl.

Dynamic intrinsic PEEP (PEEPi, dyn) was measured according to the method of Rossi et al., which assumes that the increase in airway pressure preceding inspiratory $\dot{\mathrm{V}}$ reflects the equivalent of pressure needed to counterbalance PEEPi [20].

Work of breathing was measured by graphical analysis of the esophageal pressure curve [21], and normalized for the tidal volume. Fifteen respiratory cycles were analyzed during each step of the protocol.

\section{Ventilation-perfusion (VA/Q) relationship}

The measurements of the distribution of the VA/Q ratios were performed according to the multiple inert gas elimination technique (MIGET) [22]. Six inert gases of different solubilities (SF6, ethane, cyclopropane, halothane, ether, and acetone) equilibrated in $0.9 \% \mathrm{NaCl}$ were infused at a constant rate of $3 \mathrm{ml} \mathrm{min}^{-1}$ through a central venous catheter (the Swan-Ganz introducer). After an equilibration period of $30 \mathrm{~min}$, double $10 \mathrm{ml}$ blood samples from the peripheral artery and $5 \mathrm{ml}$ blood samples from the pulmonary artery were taken into heparinized $20-\mathrm{ml}$ glass syringes. Samples of mixed expired gas were collected from the exhaust port of the ventilator into 50-ml gas-tight syringes (Hamilton 50 TLL; Hamilton, Reno, Nev., USA). Inert gas concentrations were determined with a gas chromatograph (Perkin Elmer, Shelton, Conn., USA) equipped with an electron capture detector for SF6 and a flame ionization detector for the other five gases. For each gas, retention (ratio of arterial to mixed venous concentration) and excretion (ratio of mixed expired air to mixed venous concentration) were calculated. The continuous distribution of blood flow and ventilation against the VA/Q ratios from these data were calculated by the computer program of Evans and Wagner [23]. 
Table 1 Ventilatory parameters and hemodynamics. Results are expressed as mean $\pm \mathrm{SD}$.

( $R l$ Lung resistance, $E d$ dynamic elastance, $C d$ dynamic compliance, PEEPi, dyn dynamic intrinsic positive end-expiratory pressure, $W O B$ work of breathing, $V E$ minute ventilation, $P I P$ peak inspiratory pressure, $C O$ cardiac output,

$H R$ heart rate, $M A P$ mean arterial pressure, $P A P$ mean pulmonary arterial pressure)

\begin{tabular}{|c|c|c|c|}
\hline & Baseline & $\begin{array}{l}\text { Bronchospasm } \\
\text { Air/O } \mathrm{O}_{2}\end{array}$ & $\begin{array}{l}\text { Bronchospasm } \\
\mathrm{He} / \mathrm{O}_{2}\end{array}$ \\
\hline $\mathrm{Rl}\left(\mathrm{cm} \mathrm{H}_{2} \mathrm{O} .1^{-1} . \mathrm{s}\right)$ & $6.7 \pm 1.3$ & $22.7 \pm 6^{*}$ & $16.5 \pm 3.7 *, * * *$ \\
\hline $\mathrm{Ed}\left(\mathrm{cm} \mathrm{H}_{2} \mathrm{O}^{-1} \mathrm{1}^{-1}\right)$ & $22.8 \pm 4.1$ & $76.1 \pm 11.2 * *$ & $71.1 \pm 13.1 * *$ \\
\hline $\mathrm{Cd}\left(\mathrm{l} . \mathrm{cm} \mathrm{H}_{2} \mathrm{O}^{-1}\right)$ & $0.045 \pm 0.008$ & $0.013 \pm 0.002 * *$ & $0.015 \pm 0.003 * *$ \\
\hline PEEPi, dyn $\left(\mathrm{cmH}_{2} \mathrm{O}\right)$ & $0.5 \pm 0.5$ & $3.1 \pm 0.7 *$ & $2.4 \pm 1.1$ \\
\hline WOB $\left(\mathrm{J} .1^{-1}\right)$ & $0.47 \pm 0.08$ & $1.51 \pm 0.26^{*}$ & $1.18 \pm 0.14 *, * * *$ \\
\hline VE $\left(1 . \mathrm{min}^{-1}\right)$ & $9.0 \pm 1.0$ & $9.0 \pm 1.0$ & $8.0 \pm 1.0$ \\
\hline $\mathrm{PIP}\left(\mathrm{cm} \mathrm{H}_{2} \mathrm{O}\right)$ & $18 \pm 1$ & $49 \pm 6 * *$ & $44 \pm 4 * *$ \\
\hline $\mathrm{CO}\left(1 . \mathrm{min}^{-1}\right)$ & $6.1 \pm 1.3$ & $5.5 \pm 1.4$ & $5.8 \pm 0.9$ \\
\hline HR (beats. $\min ^{-1}$ ) & $96 \pm 19$ & $116 \pm 24$ & $102 \pm 15$ \\
\hline MAP (mm Hg) & $125 \pm 13$ & $95 \pm 24$ & $96 \pm 29$ \\
\hline PAP $(\mathrm{mm} \mathrm{Hg})$ & $22 \pm 10$ & $33 \pm 12 *$ & $36 \pm 12 *$ \\
\hline
\end{tabular}

$* P<0.05$ versus baseline; $* * P<0.001$ versus baseline; $* * * P<0.05$ versus bronchospasm air/ $\mathrm{O}_{2}$

\section{Methacholine challenge}

The detailed method for performing the methacholine challenge has been described and validated in a previous study [16]. In brief, a synchronized nebulizer (ServoNebulizer 945; Siemens Elema) was connected to the ventilator's inspiratory circuit. Peak inspiratory pressure was continuously observed, methacholine was aerosolized, and its concentration was adjusted to obtain an increase in PIP up to $\pm 40 \mathrm{~cm} \mathrm{H} \mathrm{H}_{2} \mathrm{O}$. Subsequently, adjustments of methacholine concentration were performed as needed to stabilize the level of bronchospasm, stability being defined as a variation of PIP $<5 \%$ over $15 \mathrm{~min}$. Results from our previous validation study [16] showed that, once achieved, steady-state lasted for approximately 60 min without the need for further adjustments in methacholine concentration.

Measurement protocol

A complete set of all measurements described above were performed at the following time points:

1. Immediately prior to initiating the methacholine aerosolizations (air/ $\mathrm{O}_{2}$ baseline)

2. After induction of the bronchospasm, once steady-state was achieved $(68 \pm 9$ min, mean \pm SD)

3. In random order:

- After $30 \mathrm{~min}$ of air/ $\mathrm{O}_{2}$ breathing followed by $30 \mathrm{~min}$ of $\mathrm{He} / \mathrm{O}_{2}$ breathing

- After $30 \mathrm{~min}$ of $\mathrm{He} / \mathrm{O}_{2}$ breathing followed by $30 \mathrm{~min}$ of $\mathrm{He} / \mathrm{O}_{2}$ breathing

Since no statistically significant difference was noted between air $/ \mathrm{O}_{2}$ measurements during bronchospasm, results are reported as air/ $\mathrm{O}_{2}$ baseline, air $/ \mathrm{O}_{2}$ bronchospasm, and $\mathrm{He} / \mathrm{O}_{2}$ bronchospasm.

Statistical methods

Values reported in the results are expressed as mean $\pm \mathrm{SD}$. A oneway analysis of variance (ANOVA) for repeated measures was used to compare the values obtained at each of the three protocol conditions. A $P$ value $<0.05$ was considered significant. Statistics were computed using Systat 8.0 software (SPSS, Chicago, Ill., USA).

\section{Results}

Nine piglets (body weight $54.6 \pm 14.6 \mathrm{~kg}$ ) were used in the study. One animal was excluded due to the presence
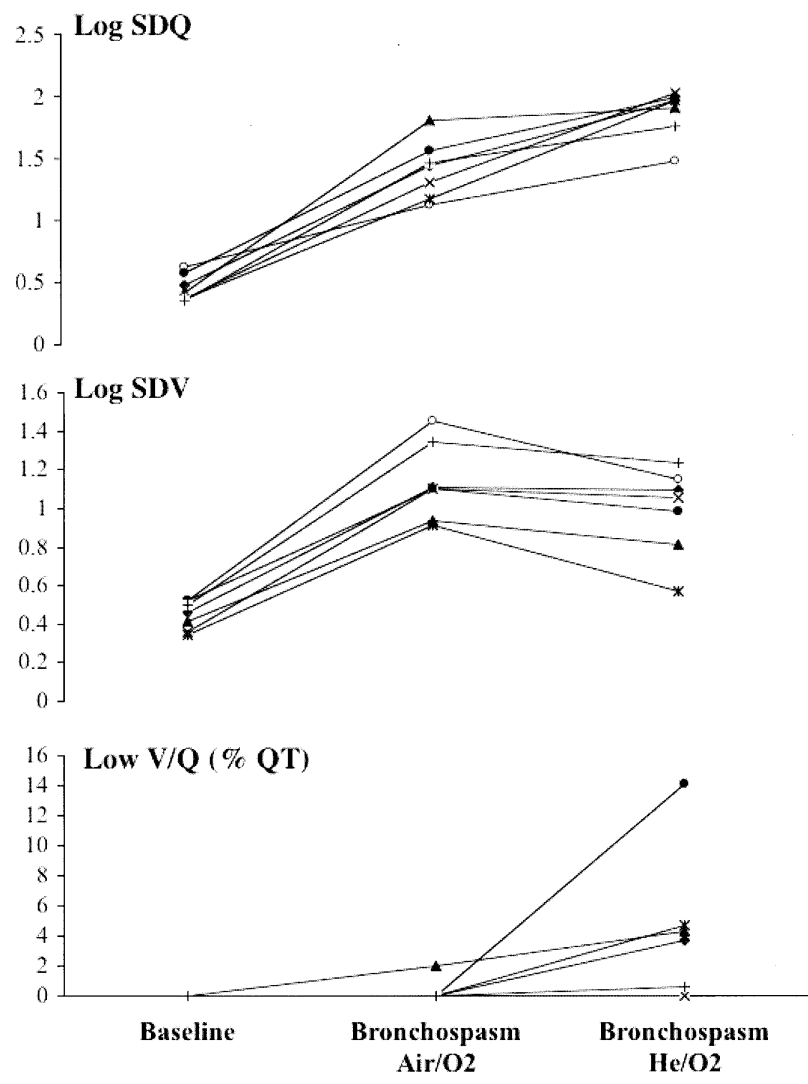

Fig. 1 Respiratory mechanics. Individual values of log standard deviations of perfusion ( $\log S D Q$, upper panel) and ventilation (Log SDV, middle panel), and percent perfusion to low V/Q regions (lower panel) in the three conditions studied

of severe hypoxemia at baseline suggesting pre-existing lung disease, and another was lost during induction of anesthesia. The seven other animals completed the study successfully. Bronchospasm led to a marked increase in peak inspiratory pressure, lung resistance, and dynamic elastance, lung resistance being lowered by $\mathrm{He} / \mathrm{O}_{2}$ (Table 1). Minute ventilation remained unchanged during all three phases, while work of breathing increased substan- 


\section{Control}
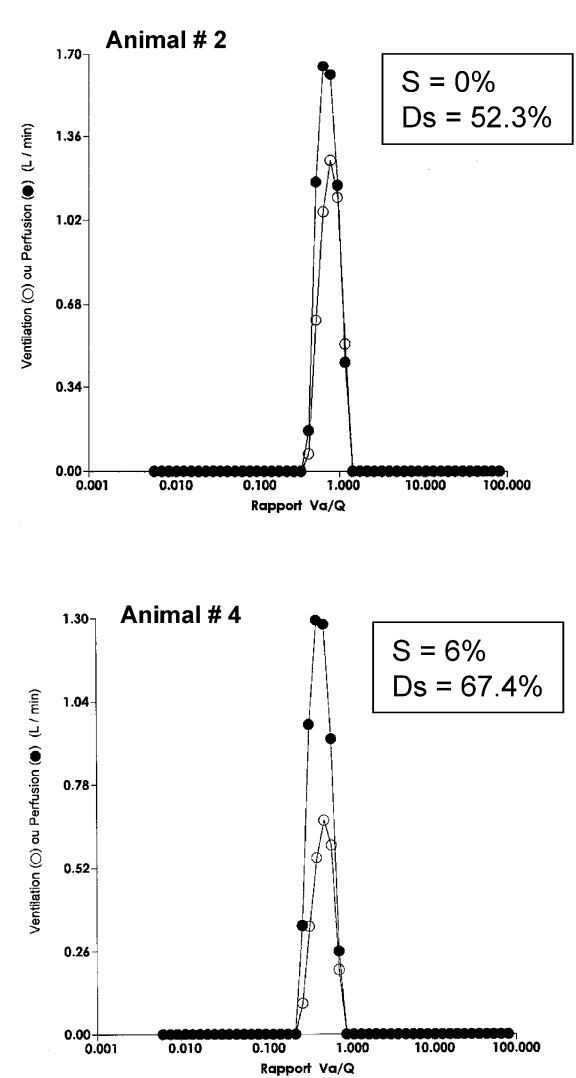

\section{Bronchospasm Air/O}
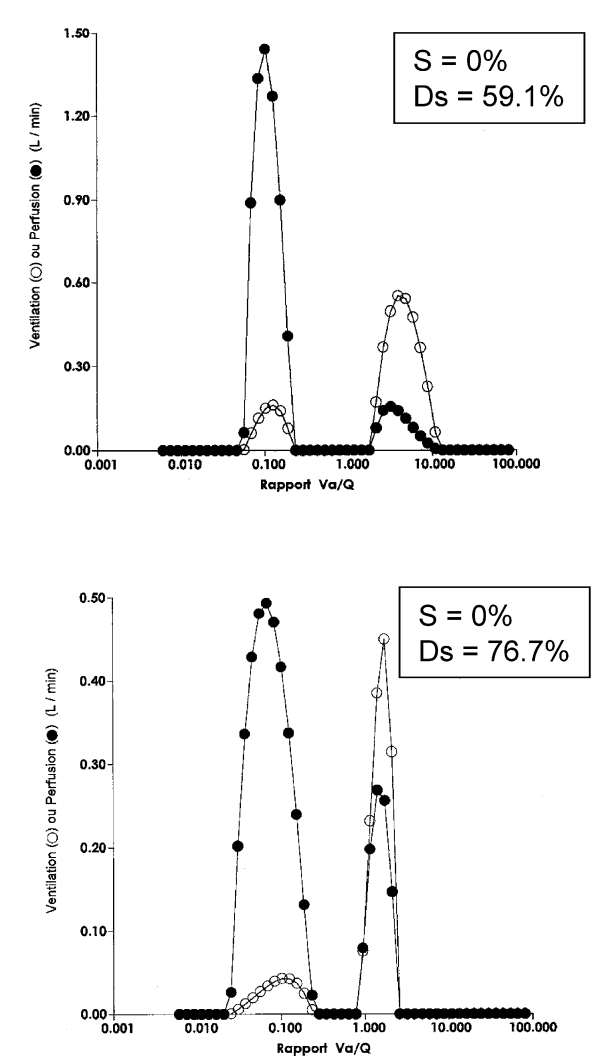

\section{Bronchospasm $\mathrm{He} / \mathrm{O}_{2}$}
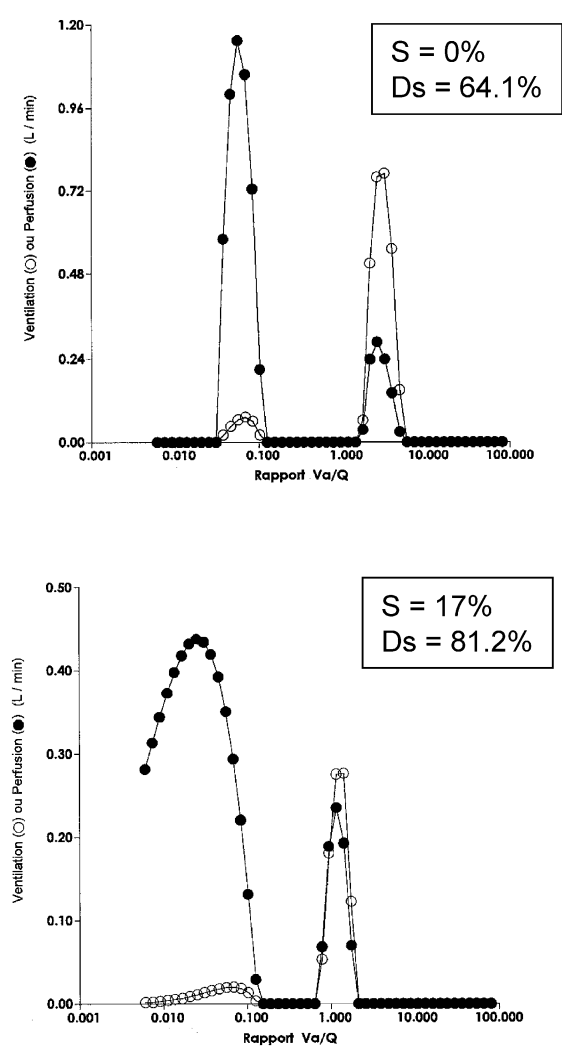

Fig. 2 Multiple inert gas elimination technique (MIGET). Ventilation (white dots) and perfusion (black dots) distribution in two representative animals in the three conditions studied. $S$ Shunt, $D s$ deadspace

tially during bronchospasm, also being reduced by $\mathrm{He} / \mathrm{O}_{2}$ (Table 1). Arterial $\mathrm{pH}$ decreased and $\mathrm{PaCO}_{2}$ increased during bronchospasm, both being further worsened by $\mathrm{He} / \mathrm{O}_{2}$, while bronchospasm-induced hypoxemia remained constant with $\mathrm{He} / \mathrm{O}_{2}$ (Table 2). No significant hemodynamic modifications other than a rise in pulmonary arterial pressure were noted (Table 1).

Results of the MIGET analysis are summarized in Fig. 1 and Table 2. As can be seen, the main ventilation abnormalities were an increase in the mean, $\log$ SD, and deadspace during bronchospasm, which remained unchanged with $\mathrm{He} / \mathrm{O}_{2}$. Perfusion data show a decrease in the mean and increase in the $\log$ SD during bronchospasm, the latter being further increased with $\mathrm{He} / \mathrm{O}_{2}$, while shunt was not significantly modified, although there was a trend towards its increase with $\mathrm{He} / \mathrm{O}_{2}$ (Table 2).

Tracings of two representative animals are shown in Fig. 2.

\section{Discussion}

The main findings of the present study are that: (1) acute bronchospasm led to a considerable increase in peak inspiratory pressure, lung resistance, and dynamic elastance, as well as hypoxemia due to decreased mean perfusion index and increased distribution of perfusion dispersion, and respiratory acidosis due to hypercapnia resulting from increased deadspace, and (2) $\mathrm{He} / \mathrm{O}_{2}$, while reducing lung resistance and work of breathing, worsened the dispersion of perfusion distribution, as well as hypercapnia and respiratory acidosis.

Let us first discuss the limitations of the study. First, the stability of such a model must be questioned. In a previous study, we demonstrated that continuously aerosolized doses of methacholine, such as administered in the present study, could lead to a stable and prolonged bronchospastic state, allowing repeated measurements over time, including MIGET [16], without the adverse hemodynamic effects of intravenous administration [24]. Furthermore, the modifications of respiratory mechanics, blood gases, and VA/Q indices observed in our previous and present studies were similar, underlining the good reproducibility of the model. Second, the validity of the 
Table 2 Arterial blood gases and MIGET results. Results are expressed as mean $\pm \mathrm{SD}$.

(DISP R-E* Index of dispersion of ventilation/perfusion ratios, corrected for deadspace, $\dot{Q} T$ pulmonary blood flow, $\dot{V}_{A} / \dot{Q}$ ventilation to perfusion ratio, $V E$ minute ventilation, $\log S D \dot{Q} \log$ standard deviation of perfusion and ventilation distribution, $R S S$ residual sum of squares)

$* P<0.05$ versus baseline $* * P<0.001$ versus baseline $* * * P<0.05$ versus bronchospasm air/O $\mathrm{O}_{2}$

\begin{tabular}{|c|c|c|c|}
\hline & Baseline & $\begin{array}{l}\text { Bronchospasm } \\
\text { Air/O }{ }_{2}\end{array}$ & $\begin{array}{l}\text { Bronchospasm } \\
\mathrm{He} / \mathrm{O}_{2}\end{array}$ \\
\hline $\begin{array}{l}\mathrm{PH} \\
\mathrm{PaO}_{2} / \mathrm{FIO}_{2}(\mathrm{~mm} \mathrm{Hg}) \\
\mathrm{PaCO}_{2}(\mathrm{~mm} \mathrm{Hg})\end{array}$ & $\begin{array}{l}7.49 \pm 0.06 \\
473 \pm 60 \\
41 \pm 6\end{array}$ & $\begin{array}{l}7.33 \pm 0.08 * * \\
160 \pm 33 * * \\
58 \pm 10 * *\end{array}$ & $\begin{array}{l}7.27 \pm 0.11 * *, * * * \\
150 \pm 35^{* *} \\
64 \pm 16^{*}\end{array}$ \\
\hline $\begin{array}{l}\text { Perfusion } \\
\text { Shunt }(\% \dot{\mathrm{QT}}) \\
0.005<\dot{\mathrm{V}}_{\mathrm{A}} / \dot{\mathrm{Q}}<0.01(\% \dot{\mathrm{Q} T}) \\
\text { Mean \% } \dot{\mathrm{Q}}\left(1 . \mathrm{min}^{-1}\right) \\
\text { LogSDQ }\end{array}$ & $\begin{array}{l}3.6 \pm 3.6 \\
0.0 \pm 0.0 \\
0.58 \pm 0.14 \\
0.45 \pm 0.11\end{array}$ & $\begin{array}{l}0.3 \pm 0.7 \\
0.3 \pm 0.8 \\
0.16 \pm 0.12 * * \\
1.41 \pm 0.24 * *\end{array}$ & $\begin{array}{l}5.1 \pm 6.8 \\
6.8 \pm 7.7 \\
0.18 \pm 0.14 * * \\
1.87 \pm 0.19 * *, * * *\end{array}$ \\
\hline $\begin{array}{l}\text { Ventilation } \\
\text { Dead space }(\% \text { VE) } \\
10<\dot{V}_{\mathrm{A}} / \dot{\mathrm{Q}}<100(\% \mathrm{VE}) \\
\text { Mean V }\left(1 . \mathrm{min}^{-1}\right) \\
\text { LogSDV } \\
\text { DISP R-E* } \\
\text { RSS }\end{array}$ & $\begin{array}{c}54.4 \pm 6.4 \\
0.1 \pm 0.2 \\
0.72 \pm 0.20 \\
0.45 \pm 0.08 \\
4.67 \pm 1.82 \\
3.99 \pm 1.85\end{array}$ & $\begin{array}{l}61.8 \pm 6.9^{*} \\
0.1 \pm 0.3 \\
1.72 \pm 0.55^{*} \\
1.14 \pm 0.20^{* *} \\
28.70 \pm 8.12^{* *} \\
4.73 \pm 1.78\end{array}$ & $\begin{array}{l}58.9 \pm 3.9 \\
3.5 \pm 7.7 \\
2.59 \pm 1.94 \\
0.98 \pm 0.30^{* *}, * * * \\
30.37 \pm 8.55^{* *} \\
3.21 \pm 1.40\end{array}$ \\
\hline
\end{tabular}

model in reproducing the conditions of mechanically ventilated ASA should be addressed. The changes we observed were comparable to those documented in other studies, with respect to arterial blood gases and VA/Q abnormalities [25, 26, 27] as well as respiratory mechanics [28]. Third, due to the complexity of the manipulations and explorations, the number of animals was small, leading to the possibility of a type II error. Finally, $\mathrm{He} / \mathrm{O}_{2}$ can interfere with various aspects of ventilator function, which can lead to changes in minute ventilation and administered $\mathrm{FIO}_{2}$ [13]. However, reliable and stable $\mathrm{He} / \mathrm{O}_{2}$ administration with the machine used in these experiments has been demonstrated, provided the appropriate correction factors are used [13].

The alterations of respiratory mechanics witnessed in the present study, i.e., increase in lung resistance and dynamic elastance during bronchospasm, are typical of observations made in two animal models $[12,28]$ as well as studies in humans $[29,30]$. In a porcine model of methacholine-induced bronchospasm, Orsini et al. showed that $\mathrm{He} / \mathrm{O}_{2}$ inhalation reduced resistance and elastance [12], whereas only resistance was improved in our study. Airway resistance is expected to decrease during $\mathrm{He} / \mathrm{O}_{2}$ inhalation due to two mechanisms. First, the lower density of the mixture reduces Reynold's number, thereby increasing the likelihood of laminar flow conditions, in which the relationship between driving pressure and flow is linear as opposed to nonlinear in turbulent flow conditions [7, 31]. Second, in areas where turbulent flow conditions prevail, the driving pressure required to obtain a given flow is reduced as density is decreased [7, 31]. Hence, both factors combine to reduce airway resistance to flow, a commonly observed manifestation of $\mathrm{He} / \mathrm{O}_{2}$ inhalation, both in normal subjects [32] and obstructive lung disease [33]. Increased elastance in asthma is thought to result from dynamic hyperinflation due to incomplete end-expiratory lung emptying $[5,6]$. Our results show a nonsignificant trend towards elastance reduction. These findings could be explained by other factors contributing to computed elastance, such as chest wall or abdominal modifications, to insufficient time of $\mathrm{He} / \mathrm{O}_{2}$ administration for more complete lung emptying to occur, or to a type II error. Regarding the former, no apparent cause was detected during the experiments, but specific measurements of intra-abdominal pressure or partitioning of respiratory mechanics were not performed, thus not allowing to rule out this hypothesis completely. The duration of $30 \mathrm{~min}$ of $\mathrm{He} / \mathrm{O}_{2}$ inhalation is consistent with the study by Orsini et al., in which elastance was significantly reduced by helium, although the model was designed differently from ours [12]. Unfortunately, even though PEEPi was not significantly reduced, no measurement of end-expiratory volume was performed, thus precluding a definite answer as to the possibility of incomplete lung emptying in our model.

Hypoxemia and hypercapnia are well known manifestations of ASA, and are in line with findings of other investigators $[10,11]$. In the study by Gluck et al., intubated and mechanically ventilated patients with status asthmaticus exhibiting hypercapnia with respiratory acidosis markedly improved both $\mathrm{pH}$ and $\mathrm{PaCO}_{2}$ after $20 \mathrm{~min}$ of $\mathrm{He} / \mathrm{O}_{2}$ inhalation [11]. In the present study, however, $\mathrm{He} / \mathrm{O}_{2}$ tended to worsen both these parameters. One possible explanation rests in the high deadspace documented in the MIGET exploration, both at baseline and in the two experimental conditions. Such a high baseline deadspace was also present in our validation study [16], and is mainly the result both from anatomical and instrumental deadspace. For $\mathrm{He} / \mathrm{O}_{2}$ to correct hypercapnia, the latter should mostly result from two causes: (1) alveolar hypoventilation due to a fall in tidal volume resulting from severe bronchospasm, the pressure limit 
on the ventilator being reached before the preset tidal volume is delivered [11], and (2) deadspace resulting from high levels of hyperinflation [34]. In both these instances, $\mathrm{He} / \mathrm{O}_{2}$, by decreasing airway resistance and hyperinflation [35], should increase alveolar ventilation and reduce deadspace, which should in turn decrease $\mathrm{PaCO}_{2}$. Regarding the first point, ventilator parameters were not modified, and minute ventilation remained unchanged during all three phases of the protocol (Table 1). As for deadspace, no modification was noted with $\mathrm{He} / \mathrm{O}_{2}$ (Table 2). However, there was a marked increase in the dispersion of VA/Q ratios (Disp R-E), during bronchospasm, which remained elevated during $\mathrm{He} / \mathrm{O}_{2}$ inhalation (Table 2). Thus, it seems that the absence of improvement of $\mathrm{PaCO}_{2}$ with $\mathrm{He} / \mathrm{O}_{2}$ probably resulted from failure of the latter to correct this major increase in Disp R-E (Table 2). The reasons for this absence of improvement is not obvious at this time.

The absence of change of $\mathrm{PaO}_{2}$ with $\mathrm{He} / \mathrm{O}_{2}$ was probably the result of several factors. Hypoxemia in patients with ASA has been shown to result from an abnormally elevated dispersion of pulmonary blood flow distribution with an increase in perfusion to low VA/Q units, in the absence of shunt $[36,37]$. In our study, the dispersion of the perfusion distribution was markedly increased by bronchospasm, and was further worsened by $\mathrm{He} / \mathrm{O}_{2}$ (Table 2), which should have worsened $\mathrm{PaO}_{2}$. Furthermore, even though statistically nonsignificant, there was a trend towards an increase in shunt with $\mathrm{He} / \mathrm{O}_{2}$, which should also have lowered $\mathrm{PaO}_{2}$. The cause for this remains speculative, but some derecruitment with $\mathrm{He} / \mathrm{O}_{2}$ could have occurred, a hypothesis we are presently investigating in the same model. Nonetheless, the effects of gas density on convective and diffusive gas transport in the lungs are quite complex [38], and conflicting results have emerged regarding $\mathrm{He} / \mathrm{O}_{2}$. He/ $\mathrm{O}_{2}$ has been shown to increase $\mathrm{PaO}_{2}$ and reduce the alveolar-arterial $\mathrm{PO}_{2}$ difference $\left(\mathrm{DA}-\mathrm{aO}_{2}\right)$ in animal studies [39], while the opposite was documented in COPD patients $[14,15]$. In two studies in COPD, one during noninvasive ventilation [40], the other in intubated, paralyzed, and mechanically ventilated COPD patients [35], no effect on $\mathrm{PaO}_{2}$ was observed. Finally, in a recent study in intubated and mechanically ventilated patients with ASA, $\mathrm{He} / \mathrm{O}_{2}$ reduced $\mathrm{DA}-\mathrm{aO}_{2}$ and increased $\mathrm{PaO}_{2}$ [41]. Thus, the difficulty of extrapolating from animal data notwithstanding, it seems that $\mathrm{He} / \mathrm{O}_{2}$ does not markedly deteriorate arterial oxygenation in this situation, due to the probable interaction of opposing mechanisms.

In conclusion, the results of this study show that, in a stable animal model of methacholine-induced bronchospasm, $\mathrm{He} / \mathrm{O}_{2}$ exerts favorable effects on airway resistance and work of breathing, but fails to improve PEEPi, arterial blood gases, and VA/Q relationships. Further studies should be conducted in this model to determine the mechanisms underlying these effects, and to explore whether they can be extrapolated to the clinical setting. Indeed, in intubated and mechanically ventilated patients with acute severe asthma, avoidance of lung damage by reducing intrathoracic pressures with $\mathrm{He} / \mathrm{O}_{2}$ still remains an attractive option, whose favorable effects could outweigh what appears to be a moderate price to pay in terms of gas exchange.

Acknowledgements This work was supported in part by the Fonds National Belge de la Recherche Scientifique, grant number 3.4506 .02

\section{References}

1. Afessa B, Morales I, Cury JD (2001) Clinical course and outcome of patients admitted to the ICU for status asthmaticus. Chest 120:1616-1621

2. Adnet F, Dhissi G, Borron SW, Galinski M, Rayeh F, Cupa M, Pourriat JL, Lapostolle F (2001) Complication profile of adult asthmatics requiring paralysis during mechanical ventilation. Intensive Care Med 27:1729-1736

3. Williams TJ, Tuxen DV, Scheinkestel GD, Czarny D, Bowes G (1992) Risk factors for morbidity in mechanically ventilated patients with acute severe asthma. Am Rev Respir Dis 146:607-615

4. Mansel JK, Stogner SW, Petrini MF, Norman JR (1990) Mechanical ventilation in patients with acute severe asthma. Am J Med 89:42-48
5. Rossi A, Polese G, Brandi G, Conti G (1995) Intrinsic positive end-expiratory pressure. Intensive Care Med 21:522-536

6. Tuxen D, Lane S (1987) The effects of ventilatory pattern on hyperinflation, airway pressures, and circulation in mechanical ventilation of patients with severe airflow obstruction. Am Rev Respir Dis 136:872-879

7. Papamoschou D (1995) Theoretical validation of the respiratory benefits of helium-oxygen mixtures. Respir Physiol 99:183-199

8. Manthous CA, Hall JB, Caputo MA, Walter J, Klocksieben JM, Schmidt GA, Wood LD (1995) Heliox improves pulsus paradoxus and peak expiratory flow in nonintubated patients with severe asthma. Am J Respir Crit Care Med 151:310-314
9. Kudukis TM, Manthous CA, Schmidt GA, Hall JB, Wylam ME (1997) Inhaled helium-oxygen revisited: effect of inhaled helium-oxygen during the treatment of status asthmaticus in children. J Pediatr 130:217-224

10. Kass JE, Castriotta RJ (1995) Heliox therapy in acute severe asthma. Chest 107:757-760

11. Gluck EH, Onorato DJ, Castriotta R (1990) Helium-oxygen mixtures in intubated patients with status asthmaticus and respiratory acidosis. Chest 98:693-698

12. Orsini AJ, Stefano JL, Leef KH, Jasani M, Ginn A, Tice L, Nadkarni VM (1999) Heliox improves pulmonary mechanics in a pediatric porcine model of induced severe bronchospasm and independent lung mechanical ventilation. Crit Care 3:65-70 
13. Tassaux D, Jolliet P, Thouret JM, Roeseler J, Dorne R, Chevrolet JC (1999) Calibration of seven ICU ventilators for mechanical ventilation with helium-oxygen mixtures. Am J Respir Crit Care Med 160:22-32

14. Manier G, Guénard H, Castaing Y, Varène N (1983) Respiratory gas exchange under heliox breathing in COPD studied by the inert gas method. Bull Eur Physiopathol Resp 19:401-406

15. Thiriet M, Douguet D, Bonnet JC, Canonne C, Hatzfeld C (1979) The effect on gas mixing of a $\mathrm{He}-\mathrm{O}_{2}$ mixture in chronic obstructive lung disease. Bull Eur Physiopathol Resp 15:1053-1068

16. Watremez C, Roeseler J, De Kock M, Clerbaux T, Detry B, Reynaert M, Gianello P, Jolliet P, Liistro G (2003) An improved porcine model of stable methacholine-induced bronchospasm. Intensive Care Med 29:119-125

17. Fry DL, Stead WW, Ebert RV, Lubin RI, Wells HS (1952) The measurement of pleural pressure and its relationship to intrathoracic pressure. J Lab Clin Med 40:664-673

18. Baydur A, Behrakis PK, Zin WA, Milic-Emili G (1982) A simple method for assessing the validity of the esophageal balloon technique. Am Rev Respir Dis 732-739

19. Lauzon AM, Bates JH (1991) Estimation of time-varying respiratory mechanical parameters by recursive leastsquares. J Appl Physiol 71:1159-1165

20. Rossi A, Gottfried SB, Zocchi L, Higgs BD, Lennox S, Calverley A, Begin P, Grassino A, Milic-Emili J (1985) Measurement of static compliance of the total respiratory system in patients with acute respiratory failure during mechanical ventilation. The effect of intrinsic positive end-expiratory pressure. Am Rev Respir Dis 131:672-677

21. Sassoon CS, Mahutte CK (1998) Work of breathing during mechanical ventilation. In: Marini J, Slutsky A (ed) Physiological basis of ventilatory support. Dekker, New York, pp 261-310
22. Wagner PD, Saltzmann HA, West JB (1974) Measurement of continuous distributions of ventilation-perfusion ratios: theory. J Appl Physiol 36:588-599

23. Evans JW, Wagner PD (1977) Limits on VA/Q distributions from analysis of experimental inert gas elimination. J Appl Physiol 42:889-898

24. Breen PH, Becker LJ, Ruygrok P, Mayers I, Long GR, Leff A, Wood LD (1987) Canine bronchoconstriction, gas trapping, and hypoxia with methacholine. J Appl Physiol 63:262-269

25. Echazaretta AL, Gomez FP, Ribas J, Sala E, Barbera JA, Roca J, RodriguezRoisin R (1991) Pulmonary gas exchange responses to histamine and methacholine challenges in mild asthma. Eur Respir J 17:609-614

26. Rodriguez-Roisin R, Ballester E, Roca J, Torres A, Wagner PD (1989) Mechanisms of hypoxemia in patients with severe status asthmaticus requiring mechanical ventilation. Am Rev Respir Dis 139:732-739

27. Rodriguez-Roisin R, Ferrer A, Navajas D, Agusti AG, Wagner PD, Roca J (1991) Ventilation-perfusion mismatch after methacholine challenge in patients with mild bronchial asthma. Am Rev Respir Dis 144:88-94

28. Rubinfeld AR, Wagner PD, West JB (1978) Gas exchange during acute experimental canine asthma. Am Rev Respir Dis 118:525-536

29. Martin JG, Shore SA, Engel LA (1983) Mechanical load and inspiratory muscle action during induced asthma. Am Rev Respir Dis 128:455-460

30. Wheatley JR, West S, Cala SJ, Engel GA (1990) The effect of hyperinflation on respiratory muscle work in acute $\mathrm{i}$ nduced asthma. Eur Respir J 3:625632

31. O’Grady K, Doyle DJ, Irish J, Gullane P (1997) Biophysics of airflow within the airway: a review. J Otolaryngol 26:123-128

32. Otis AB, Bembower WC (1949) Effects of gas density on resistance to respiratory gas flow in man. J Appl Physiol 2:300-306
33. Grapé B, Channin E, Griffin P (1960) The effect of helium and oxygen mixtures on pulmonary resistances in emphysema. Am Rev Respir Dis 81:823-829

34. Connors AF, McCaffee DR, Gray BA (1981) Effect of inspiratory flow rate on gas exchange during mechanical ventilation. Am Rev Respir Dis 124:537-543

35. Tassaux D, Jolliet P, Roeseler J, Chevrolet JC (2000) Effects of heliumoxygen on intrinsic positive end-expiratory pressure in intubated and mechanically ventilated patients with severe chronic obstructive pulmonary disease. Crit Care Med 28:2721-2728

36. Rodeberg DA, Easter AJ, Washam MA, Housinger TA, Greenhalgh DG, Warden GD (1995) Use of a heliumoxygen mixture in the treatment of postextubation stridor in pediatric patients with burns. J Burn Care Rehabil 16:476-490

37. Rodriguez-Roisin R (1997) Acute severe asthma: pathophysiology and pathobiology of gas exchange abnormalities. Eur Respir J 10:1359-1371

38. Schulz H, Schulz A, Eder G, Heyder J (1995) Influence of gas composition on convective and diffusive intrapulmonary gas transport. Exp Lung Res 21:853-876

39. Erickson BK, Seaman J, Kubo K, Hiraga A, Kai M, Yamaya Y, Wagner PD (1994) Mechanism of reduction in alveolar-arterial $\mathrm{PO}_{2}$ difference by helium breathing in the exercising horse. J Appl Physiol 76:2794-2801

40. Jolliet P, Tassaux D, Thouret JM, Chevrolet JC (1999) Beneficial effects of helium-oxygen vs. air-oxygen noninvasive pressure support in decompensated COPD patients. Crit Care Med 27:2422-2429

41. Schaeffer EM, Pohlman A, Morgan S, Hall JB (1999) Oxygenation in status asthmaticus improves during ventilation with helium-oxygen. Crit Care Med 27:2666-2670 